\title{
An Ultraviolet C-Band LED device for disinfection of air, articles and indoor environment
}

\author{
Anwesh P. Sahu \\ ar75 Rosemar Ct, San Jose, CA 95127, USA
}

\begin{abstract}
Background: Commonly used items like wallets, keys, and phones are both tricky and impractical to disinfect from the dangers of harmful microbes. This study demonstrates the efficacy of UVC-LED technology in creating an efficient, useful, and practical solution.
\end{abstract}

Methods: As a demonstration of the efficacy of the UVC-LED light (275 $\mathrm{nm}$ ), a panel of UVC LEDs was fabricated and was driven with a constant current electronic driver. Staphylococcus aureus and Escherichia coli were placed on Petri dishes, and placed $38 \mathrm{~cm}$ away from the UVC-LED panel. UVC flux measured at the petri dishes was $0.093 \mathrm{~mW} / \mathrm{cm} 2$. The method involved exposing both the bacteria to UVC treatment for 4 and 8 minutes. For each petri dish, the number of colony forming units were compared before and after the treatment and compared to the control.

Results: A significant reduction in colony forming unit (cfu) counts was found in all samples for both sets of bacteria: $97.9 \%$ in the 4 minutes treat$\operatorname{ment}\left(22.3 \mathrm{~mJ} / \mathrm{cm}^{2}\right)$, and $99.9 \%$ in the 8 minutes treatment $\left(44.6 \mathrm{~mJ} / \mathrm{cm}^{2}\right)$.

Conclusion: UVC-LED technology offers an effective, simple and inexpensive approach for disinfection.

Keywords: UV-LED, UVC, Disinfection, Sanitization, Biotechnology

Email address: anwesh2004@gmail.com (Anwesh P. Sahu) 


\section{Background}

Given the relentless waves of viral and bacterial outbreaks with high fatality rates and contagiousness, it seems imperative that there be ways for all people to safely, effectively and conveniently disinfect surfaces and objects around them. For example, in 2009, the H1N1 flu pandemic caused over 250,000 deaths; in between 2014 and 2016, the Ebola outbreak caused over 11,000 deaths. In 2020 alone, COVID-19(SARS-CoV-2) has caused over 5 million deaths. These outbreaks are do not only cause massive loss of lifethey cause immense economic damage to the global economy. Many of these deaths and illnesses could have been prevented with widespread use of more efffective disinfecting devices.

Outbreaks are mainly spread by contact or close proximity with other people, in often benign interactions - those that are not thought about or are paid little heed to, such as giving a grocer your credit card or shaking hands with a neighbor. Disinfection, even when using the right disinfectants is both tricky and impractical in many situations.

UVC LED technology, however, appears to be a useful solution in recent years, as research shows the antimicrobial properties of UVC technology, and its application in the disinfection of stethoscopes from nosocomial infections[1]. UV light has already been used for such therapeutic purposes as stimulating vitamin D production and treating psoriasis, as well as for sanitizing air, water, and the environment[2]. At its typical wavelength of $200-280 \mathrm{~nm}$, UVC radiation induces pyrimidine dimers in thymine and 
cytosine, breaking DNA molecules, inactivating germs and preventing them from growing or reproducing[3].

\section{Methods}

\subsection{LED \& Driver}

The commercial packaged UVC LED was obtained from Shenzhen Sxstrong Technology Co.[4], with part number SXS-S3535UVC-20. It packages the bare chip PCD-10-V1 produced by Photon Wave Co. [5]. Optical spectrum of the LED emission was measured with a UV-VIS spectrophotometer FLAME-S-UV-VIS from Ocean Insight [6] calibrated with a DH-3 Plus UV-VIS-NIR light source producred from the same vendor. The emission spectrum is shown in Figure 1.

Important performance specifications of the LED are reproduced here from the manufacturer's datasheet: Peak Wavelength $=275 \mathrm{~nm}$; Full Width at Half Maximum $(\mathrm{FWHM})=11 \mathrm{~nm}$; Output Optical Power $=15 \mathrm{~mW}$; Typical Forward Voltage $=5.7 \mathrm{~V}$; Viewing Angle $\left(2 \times \theta_{1 / 2}\right)=125^{\circ}$.

For the puposes of this device, these UVC LEDs were arranged in a matrix of five-in-series and five-in-parallel (5S-5P) configuration on a Printed Circuit Board (PCB) Panel of dimension $22 \mathrm{~cm} \times 12 \mathrm{~cm}$. As shown in Figure 2, five LEDs were connected in series with a balancing resistor or $10 \Omega$ to form one arm. Five such arms were connected in parallel. These 25 LEDs were arranged uniformly on the $\mathrm{PCB}$ panel to provide uniform illumination to the working surface. 


\subsection{Controller}

The LED matrix was driven with a Constant-Current Constant-Voltage (CC-CV) driven. Circuit design of the LED driver is shown in Figure 3. The main control loop is provided by an LED Boost Driver chip RT8485 [7], which takes a $12 \mathrm{~V}$ wall power supply as input and provides a constant current boosted output on the terminal VLED, which in turn is connected to the LED matrix. In the given configuration, the circuit provides $500 \mathrm{~mA}$ of constant current at a maximum voltage of $30 \mathrm{~V}$. These output values may be changed by tuning the resistors R3A, R3D and R3E, formulatory guidances for which are given in the figure itself.

Further, the current output, and consequently the LED optical output can be modulated by providing a Pulse Wave Modulation (PWM) signal at the LEDCTL input of the circuit. The duty factor of the PWM signal

modulates the output current. A PWM signal of frequency between 100 and $1000 \mathrm{~Hz}$ with a PWM range of $0-100 \%$ has been tested with this circuit. In a practical circuit, the LEDCTL PWM singal is typically provided from a micro-controller.

\subsection{Battery Backup for Portability}

It was determined that making the device function untethered to a wall supply would make it highly portable, and with appropriate personal protection, the device could be carried around to disinfect areas and objects at places other than the main device. A battery pack was therefore built and 
integrated with the electronics to provide such a backup power supply.

Six cylindrical 18650-F5P Lithium NCM rechargeable cells from Cham[8] were connected in a three-in-series and two-in-parallel (3S-2P) configuration. Each of these cells are $18 \mathrm{~mm}$ in diameter and $65 \mathrm{~mm}$ in length, and have a nominal voltage of $3.7 \mathrm{~V}$ with a nominal capacity of $2.2 \mathrm{Ah}$. In this implementation, each cell was allowed to charge up to $4 \mathrm{~V}$ and discharge down to $3 \mathrm{~V}$. So, in the $3 \mathrm{~S}$ configuration, the maximum and minimum voltages were $12 \mathrm{~V}$ and $9 \mathrm{~V}$, respectively.

The cells are tabbed into a 3S-2P configuration, pigtailed, and packed into a plastic case with hot-melt adhesive dispensed into the case. The pigtail connections are: $3+, 2+, 1+$ and $1-$, with maximum voltages of $12 \mathrm{~V}, 8 \mathrm{~V}, 4 \mathrm{~V}$ and $0 \mathrm{~V}$, respectively.

In the control circuit of the device, provisions are made to linearly charge the battery pack from the wall supply, monitor the voltages, and balance the cells. Algorithms are also implemented in the microcontroller to estimate the State of Health of the battery pack, and report to the user in the event of a change of battery is warranted. These circuit diagrams and algorithmns are out of scope of the theme of this paper, but could be provided upon request to the author.

\subsection{Construction Materials \& System Integration}

Different views of the device are shown in Figure 4. The device consists of two sections : Detachable Lid and Sanitization Bin. 
The Detachable Lid contains the UVC LED panel on the inside. On the outside, it has an LCD status screen, a control switch, a handle, and a fan. Hidden away from the view, behind the LED panel are a control board and the battery pack. The control board consists of the LED driver discussed earlier, and a micro-controller that controls/reads the LED Driver, switch, LCD, fan and any interlocking mechanisms. In this device the microcontroller PIC18F45Q10 from Microchip[9] was used. The Detachable Lid is molded out of ABS-PC.

The Sanitization Bin is molded out of ABS-PC, but is loaded with 3.5\% Barium Sulfate $\left(\mathrm{BaSO}_{4}\right)$ powder with mean diamter of $1.2 \mu \mathrm{m}$. Barium Sulfate is known to increase the refectivity of UV-C band light[10], which would increase and reuse the flux of light incident on objects placed in the bin. Bottom of the Sanitization Bin has several vent holes. Ambient air is drawn into the device with the fan (at a speed of up to $30 \mathrm{ft}^{3} / \mathrm{min}$ ), partially sanitized in the volume of the device and blown out back into the ambient through these vent holes, thus cycling and sanitizing the ambient air.

A pair of straps, when engaged, keep the Detachable Lid and Sanitization Bin together so that the unit can be carries around with the handle.

The Detachable Lid itself can be carried around with the handle and used to disinfect objects and surfaces other than those placed in the Sanitization Bin. 


\section{Results}

Killing rates for the two different germs for two different UVC exposure times are summarized in Table 1.

It may be observed that while a $4 \mathrm{~min}$ exposure (dose of $22.3 \mathrm{~mJ} / \mathrm{cm}^{2}$ )

gets a decent killing rate of about 98\%, an $8 \mathrm{~min}$ exposure (dose of 44.6 $\mathrm{mJ} / \mathrm{cm}^{2}$ ) offers an almost perfect disinfection at $99.9 \%$ log reduction.

\section{Discussion}

The MF-SAN device operating on the principle of UVC-LED technology can be used in many different ways.

The device as it is can be used to sanitize the room air. The fan draws the air in through the top, and blows it through the bottom vent holes, while the UVC-LEDs sanitize the air in the volume of the device. It is estimated that a room of size $15^{\prime}$ x $10^{\prime} \times 10^{\prime}$ can be sanitized at $>98 \%$ within 15 minutes.

The device can be be used to sanitize a number of different objects, such as utensils, phones, personal items, fruits \& vegetables, as shown in Figure 5.

The device can also be used as a portable UVC gun to disinfect highcontact surfaces, such as in clinics and offices, as shown in Figure 6.

It has been estimated that the MF-SAN device may be produced rather inexpensively. At a production quantity of 10,000 units, the cost is estimated to be about USD 150 per unit. 


\section{References}

[1] G. Messina, S. Burgassi, D. Messina, V. Montagnani, G. Cevenini, A new UV-LED device for automatic disinfection of stethoscope membranes, American Journal of Infection Control 43 (2015) E61-E66. doi:http://dx.doi.org/10.1016/j.ajic.2015.06.019.

[2] L. C. Kloth, Physical modalities in wound management: UVC, therapeutic heating and electrical stimulation, Ostomy Wound Manage 41(5) (1995) 18-20.

[3] T. Dai, M. S. Vrahas, C. K. Murray, M. R. Hamblin, Ultraviolet C irradiation: an alternative antimicrobial approach to localized infections?, Expert Rev Anti Infect Ther. 10(2) (2012) 185-192. doi:10.1586/eri.11.166.

[4] Shenzhen Sxstrong Technology Co., Shenzhen, China.

[5] Photon Wave, 52, Jugyang 1763 beon-gil, Wonsam-myeon, Cheoin-gu, Yongin-si, Gyeonggi-do, 17166 South Korea.

[6] Ocean Insight, 3500 Quadrangle Blvd, Orlando, FL 32817 USA.

[7] Richtek, 14F, No.8, Tai Yuen 1st Street, Chupei City, Hsinchu, Taiwan 30288.

[8] DongGuan Cham Battery Technology Co., No 9, Third West Industry Road, Songshan Lake High-Tech Industrial Development Zone, DongGuan, GuangDong, China. 
[9] Microchip, www.microchip.com.

[10] N. Knighton, B. Bugbee, A mixture of barium sulfate and white paint is a low-cost substitute reflectance standard for spectralon, Techniques and Instruments 11 (2005).

URL https : //digitalcommons.usu.edu/cpl_techniquesinstruments/11 


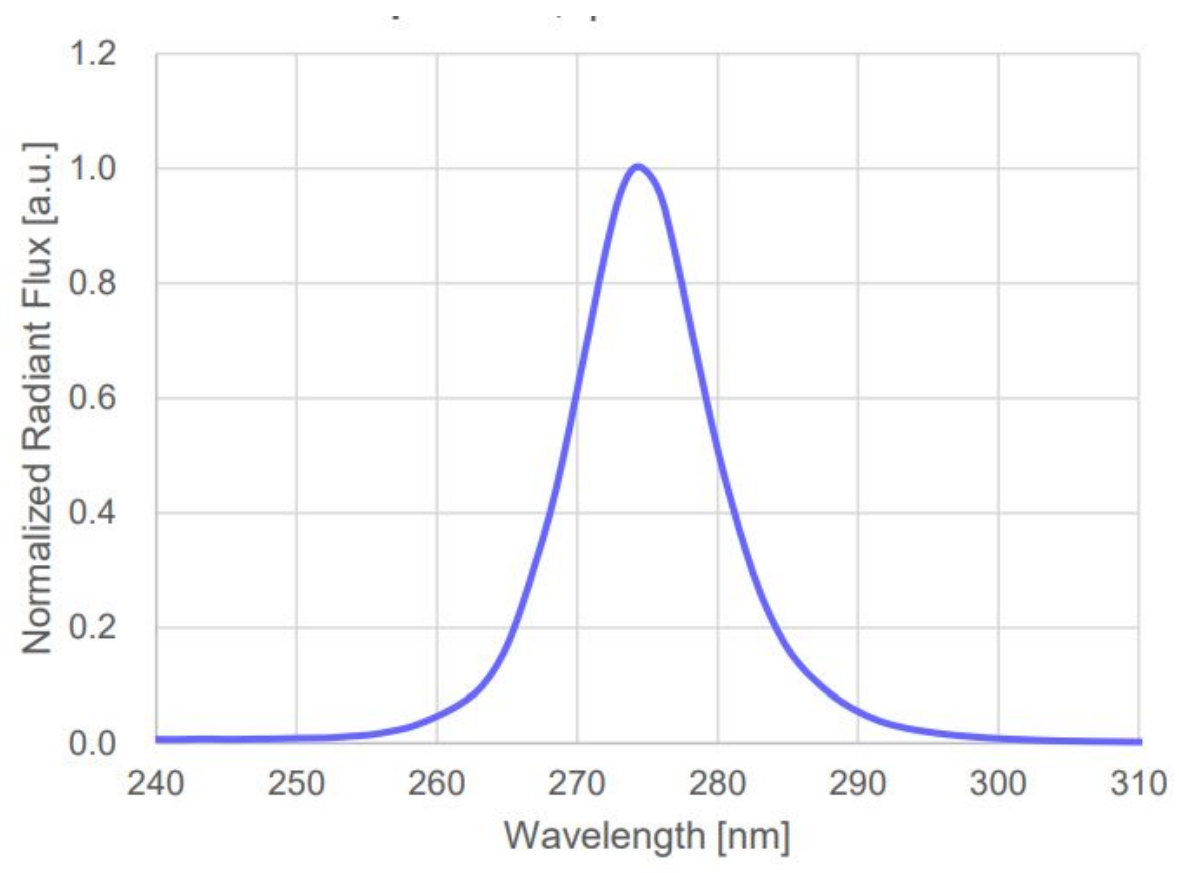

Figure 1: Optical emission spectrum of the UVC LED used in this device. 


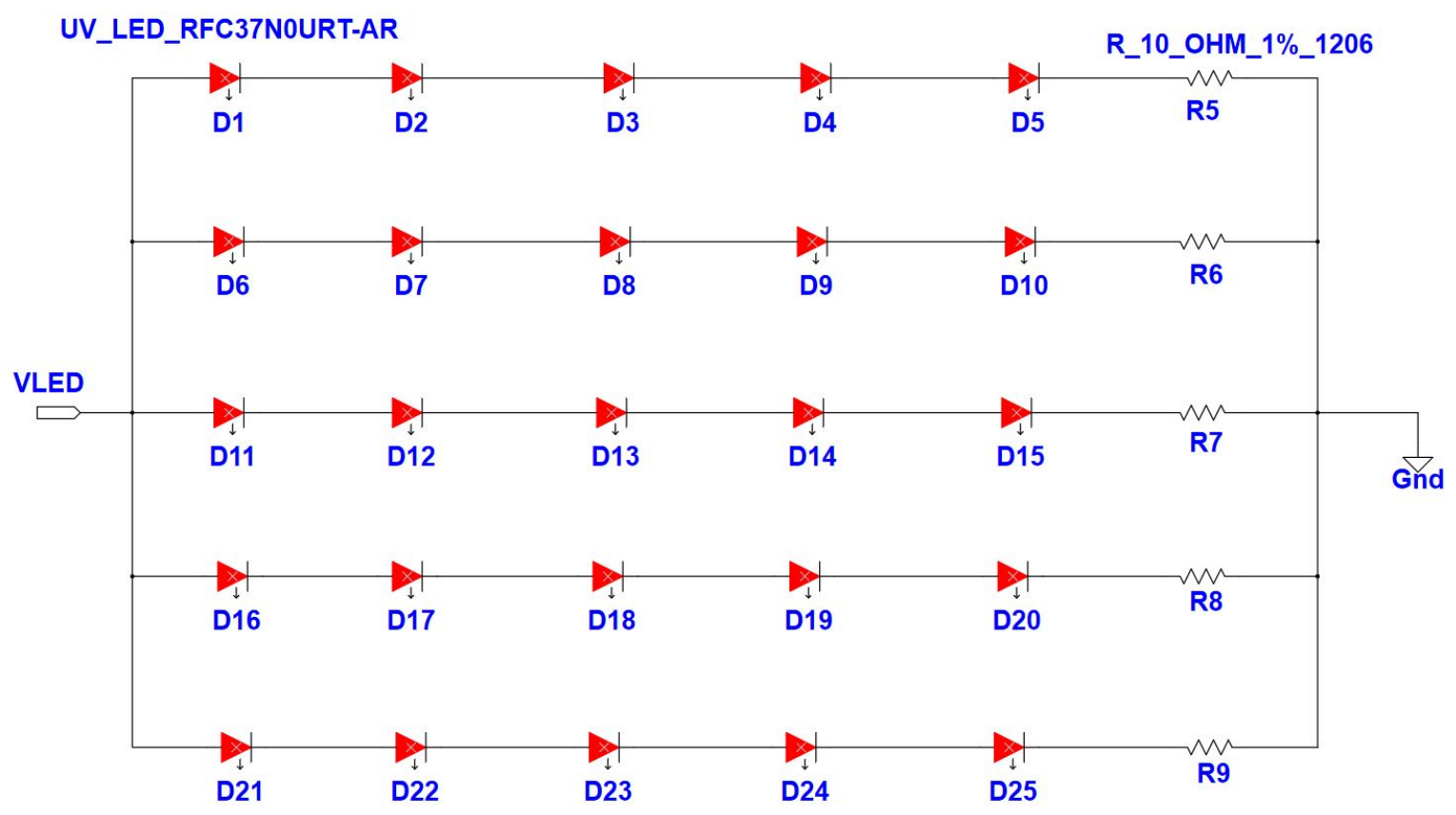

Figure 2: Electrical configuration of UVC LED array. 


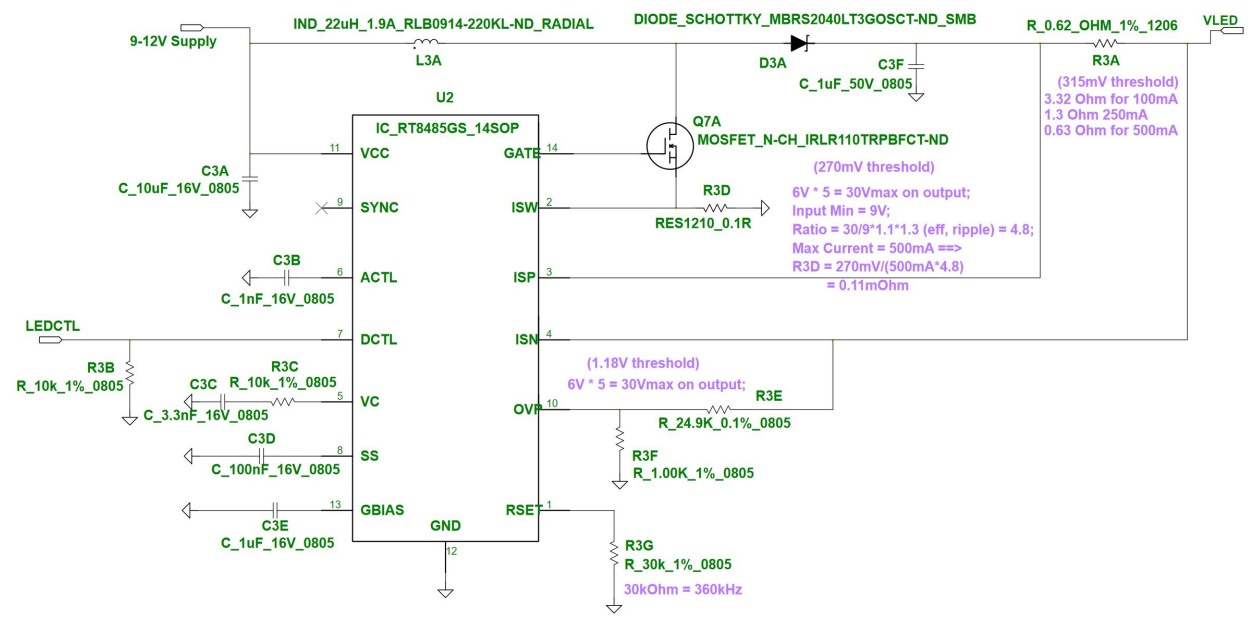

Figure 3: Modulated Constant Current Driver circuit for UVC LED array. 

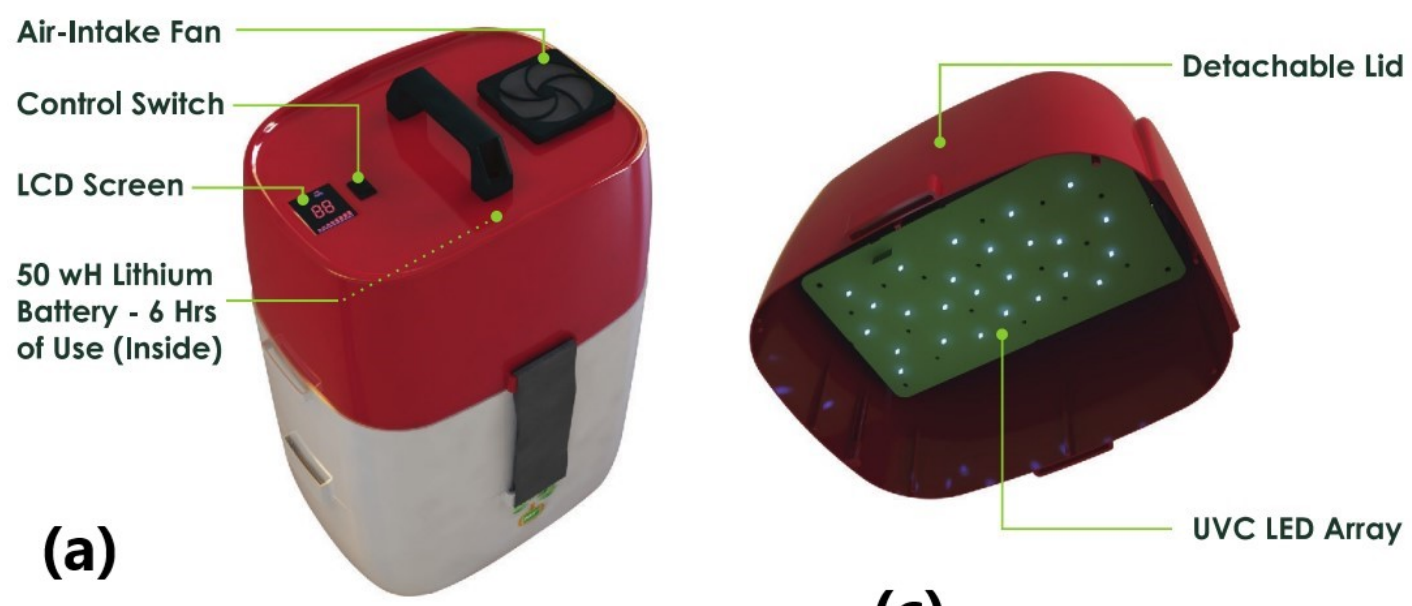

(c)

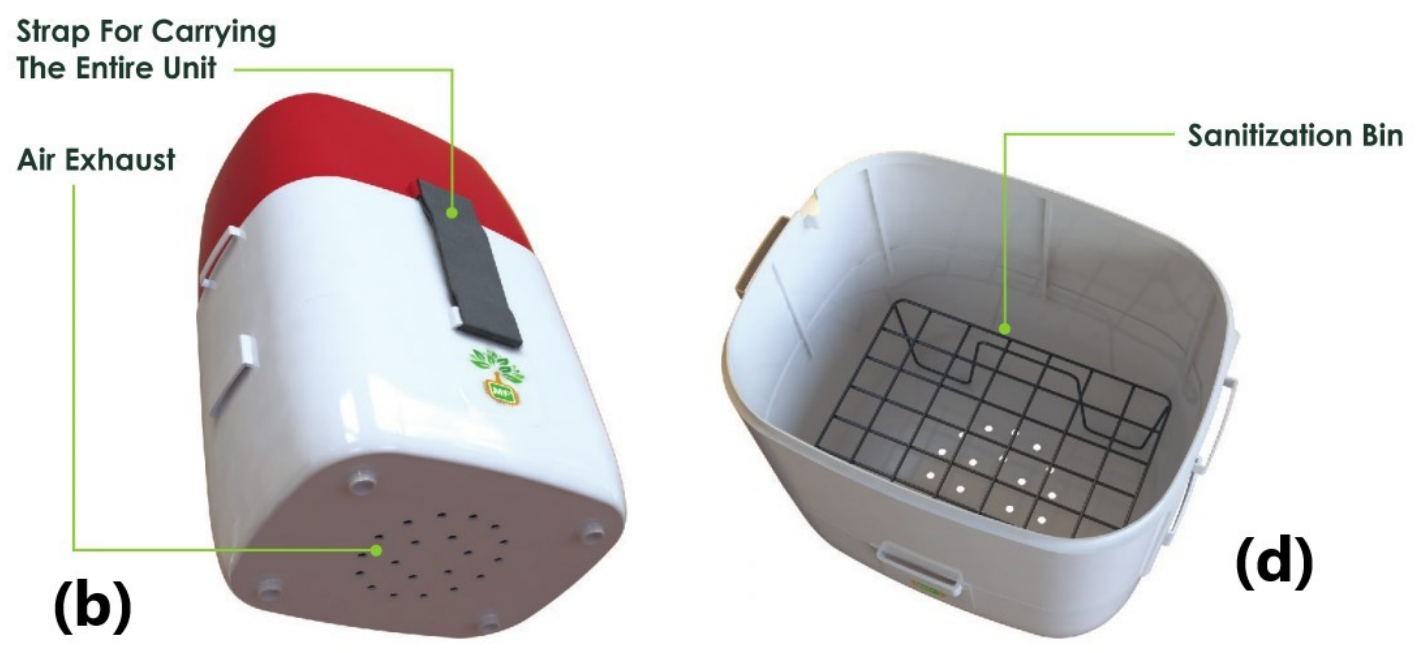

Figure 4: Photos of the final system. (a) Top isometric view of the device; (b) Bottom isometric view of the device; (c) Detachable Lid; (d) Sanitization Bin. 


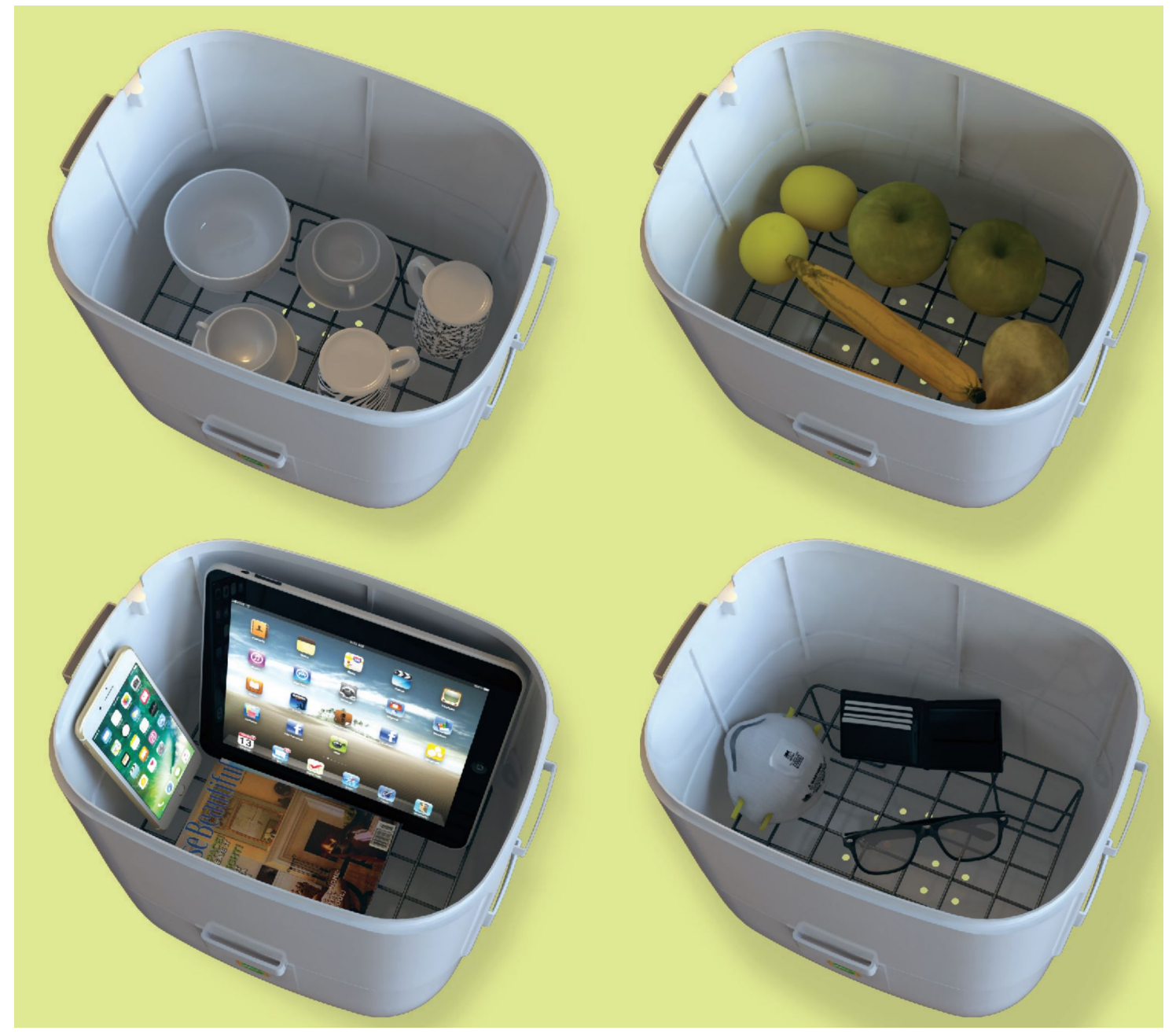

Figure 5: Many types of objects can be disinfected with MF-SAN. 


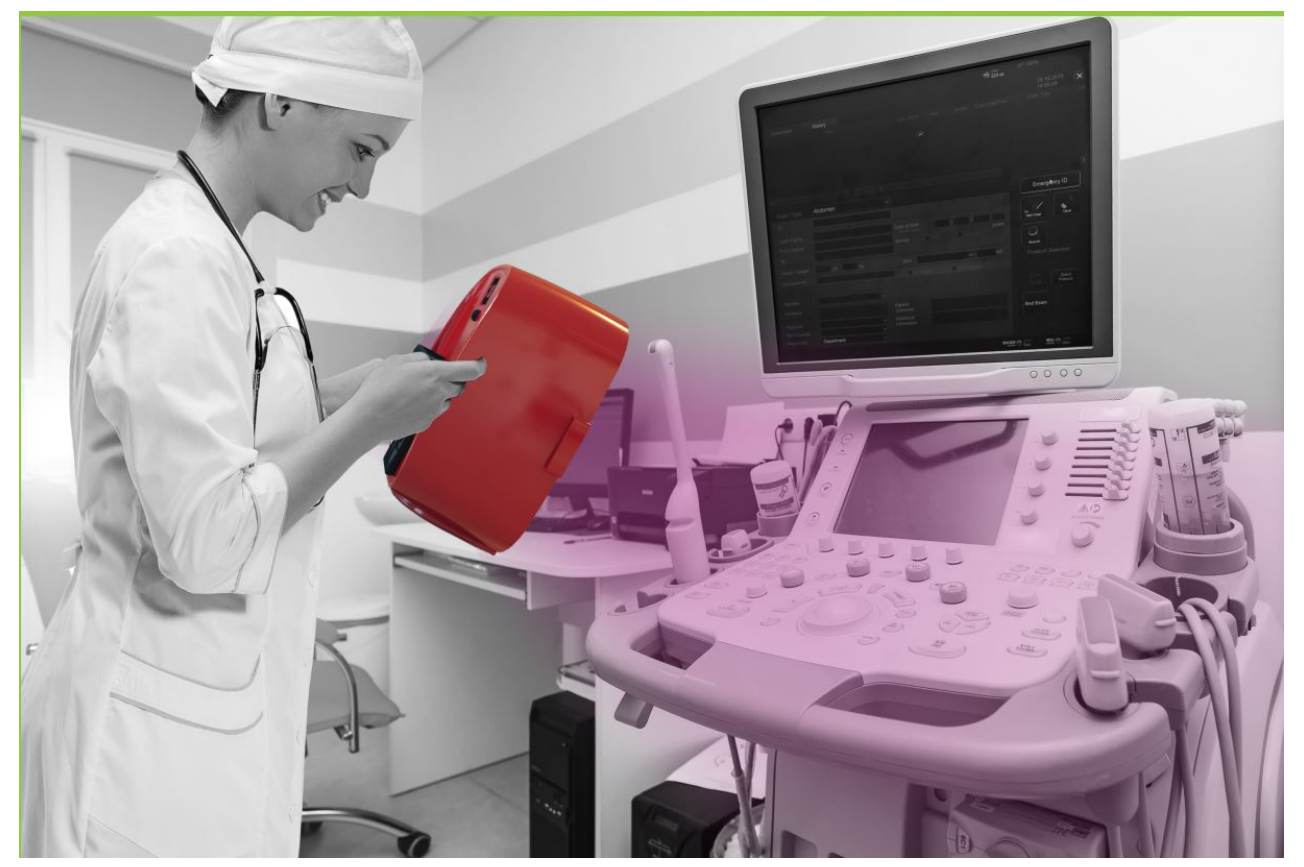

Figure 6: High-contact surfaces can be disinfected by using the MF-SAN in batterysupported portable mode. 


\begin{tabular}{|l|l|l|l|l|l|l|}
\hline $\begin{array}{l}\text { Test Or- } \\
\text { ganism }\end{array}$ & $\begin{array}{l}\text { Time } \\
\text { of Ex- } \\
\text { posure } \\
(\mathrm{min})\end{array}$ & $\begin{array}{l}\text { UVC } \\
\text { dose } \\
\left(\mathrm{mJ} / \mathrm{cm}^{2}\right)\end{array}$ & $\begin{array}{l}\text { Control } \\
\text { count } \\
(\mathrm{cfu} / \mathrm{ml})\end{array}$ & $\begin{array}{l}\text { Count } \\
\text { for irra- } \\
\text { diated } \\
\text { samples } \\
(\mathrm{cfu} / \mathrm{ml})\end{array}$ & $\begin{array}{l}\text { Killing } \\
\text { Rate }\end{array}$ & $\begin{array}{l}\text { Average } \\
\text { Killing } \\
\text { Rate }\end{array}$ \\
\hline E. coli & 4 & 22.3 & $\begin{array}{l}2600 \\
2400\end{array}$ & $\begin{array}{l}49 \\
58\end{array}$ & $\begin{array}{l}98.1 \% \\
97.6 \%\end{array}$ & $97.9 \%$ \\
\hline E. coli & 8 & 44.6 & $\begin{array}{l}2600 \\
2400\end{array}$ & $\begin{array}{l}2 \\
3\end{array}$ & $\begin{array}{l}99.9 \% \\
99.9 \%\end{array}$ & $99.9 \%$ \\
\hline S. aureus & 4 & 22.3 & $\begin{array}{l}2100 \\
2800\end{array}$ & $\begin{array}{l}52 \\
48\end{array}$ & $\begin{array}{l}97.5 \% \\
98.3 \%\end{array}$ & $97.9 \%$ \\
\hline S. aureus & 8 & 44.6 & $\begin{array}{l}2100 \\
2800\end{array}$ & $\begin{array}{l}2 \\
3\end{array}$ & $\begin{array}{l}99.9 \% \\
99.9 \%\end{array}$ & $99.9 \%$ \\
\hline
\end{tabular}

Table 1: Killing Rate of E. coli and S. aureus for different UVC exposure doses. Incident UVC flux at the working surface was $0.093 \mathrm{~mW} / \mathrm{cm}^{2}$. 